\title{
EDUCAÇÃO ÉTNICO-RACIAL E INTERCULTURALIDADE CRÍTICA NA ESCOLA: FORMAÇÃO INICIAL DE PROFESSORES POR MEIO DO PIBID/UNIRIO
}

\author{
Maria Elena Viana Souzai \\ Andrea Rosana Fetznerii
}

\begin{abstract}
Resumo: Este trabalho discute as relações raciais no cotidiano escolar e a formação inicial de professores de forma concomitante à prática de ensino nas escolas. Trata-se de experiência desenvolvida no ensino superior, em Curso de Pedagogia, por meio do Programa Institucional de Bolsa de Iniciação à Docência - PIBID/UNIRIO. São descritas possibilidades e problematizações do processo formativo. Analisa tais descrições por meio da interculturalidade crítica que vê os conhecimentos escolares como suspeitos de servirem a interesses específicos. Percebe-se que, além de dar uma atenção especial aos currículos dos cursos de formação de professores, é preciso se preocupar com a possibilidade de potencializar o pensar crítico na formação dos professores que já estão vivenciando o magistério.
\end{abstract}

Palavras-chave: Relações raciais; Formação de professores; Interculturalidade Crítica; Saberes.

\section{ETHNIC-RACIAL AND INTERCULTURAL EDUCATION CRITICISM AT SCHOOL: INITIAL TRAINING OF TEACHERS THROUGH THE pibid/unirio}

\begin{abstract}
This work discuss race relations in daily life and the initial training of teachers in order to practice teaching in concomitant schools. It is a question of experience developed in higher education, ongoing education, through the Institutional Program of Scholarship of Teaching beginners-PIBID. There are described possibilities and problems envolving formation process. Analyzed descriptions the critical knowledge seen in intercultural schools as suspects they serve the specific interests. Notice that, in addition to giving a special attention to curriculum of training courses for teachers, need to worry about the possibility of enhancing critical thinking on training teachers who are already experiencing the Magisterium.
\end{abstract}

Keywords: Race relations; Training of teachers; Interculturality Critical; Knowledge.

\section{Introdução}

Este artigo propõe discutir a formação inicial de professores, por meio do Pibid/UNIRIO, para o trabalho com a educação étnico-racial na escola de ensino fundamental. Para isto, apresenta-se a perspectiva intercultural crítica na formação de professores, mais 
especificamente, no âmbito da formação de pedagogos. No desenvolvimento do artigo, abordase a compreensão das relações entre educação e cultura e como esta compreensão pode contribuir na abordagem da temática racial nas escolas.

Por fim, apresenta-se a experiência desenvolvida em 2012, em Curso de Pedagogia, com 12 estudantes participantes do Programa Institucional de Bolsa de Iniciação à Docência PIBID/UNIRIO - que foram provocadas a trabalhar com a temática racial nas escolas. Como resultados, apresentam-se algumas práticas desenvolvidas e alguns cuidados que são considerados necessários para a qualificação da formação oferecida.

Freitas (2004), ao criticar as políticas de formação expressas no aligeiramento da formação inicial, no caráter técnico-profissionalizante predominante nos discursos e legislações, na adoção da educação a distância como mecanismo de expansão da formação para professores em serviço e na incorporação do conceito de regulação como orientação das ações - lógica da competitividade, da adaptação individual aos processos sociais e ao desenvolvimento de suas competências para a empregabilidade ou laboralidade (p. 101) -defende a necessidade de contemplar a formação de forma a desenvolver concepções de percurso de formação em instituições universitárias que articulem ensino-pesquisa-extensão (p.109) e, como percursos de formação com projetos pedagógicos próprios, alternativas curriculares que

[...] possibilitem o desenvolvimento de conteúdos e metodologias que traduzam as formas de pensar e atuar ante problemas concretos da vida social; a formação teórica e epistemológica aliada ao domínio técnico e científico do conhecimento mais avançado e progressista produzido nas condições atuais.(Idem)

Compartilha do entendimento que a pesquisa deve ser a base de formação do pedagogo e que a formação precisa contribuir com a formação crítica e emancipatória destes, no sentido de instrumentalizá-los para a ação prática transformadora e autônoma do ponto de vista intelectual, ou seja, a compreensão que se compartilha neste momento entende que o saber pedagógico, por focar-se nos processos educacionais desenvolvidos pela humanidade, na sociedade, no trabalho e também nas escolas, inclui saberes que são específicos, como os organizacionais didáticos, por exemplo, e culturais e políticos, como o estudo do sentido das instituições educativas, seus fins declarados e efetivos, entre outros. Portanto, o saber pedagógico não seria apenas o saber que conduziria à prática reflexiva sobre as práticas educativas, conforme algumas correntes percebem, hoje, a formação (BREZINSKI, 2008) pois 
que, para realizá-la são necessários base epistemológica, métodos investigativos e compreensões culturais e políticas que não se reduzem à análise apenas dos próprios processos educacionais, mas das intencionalidades da sociedade e dos processos educacionais decorrentes destas intencionalidades.

Desde uma perspectiva crítica e emancipatória, Freitas (2004) indicava a necessidade da compreensão do sentido ideológico da educação, uma vez que os sentidos possíveis são disputados politicamente. Assim, uma concepção omnilateral da formação humana: cognitiva, ética, política, científica, cultural, lúdica e estética (p.108), que possibilitem ao professor construir novas relações na escola pública, que permitam aflorar processos de formação humana criativos, emancipadores e criadores de uma nova vida (p.111) torna-se fundamental para não minimizar o docente e, ao mesmo tempo, embasar o trabalho profissional.

Outro olhar que também indica a pesquisa como espaço importante na formação de professores tem base nos estudos com o cotidiano. Garcia e Alves (2012), que ressaltam a relevância da compreensão do cotidiano escolar no trabalho docente, destacam:

as pesquisas com o cotidiano têm assumido a necessidade de ações de pesquisa na formação de professores - já falamos no "componente curricular" PPP (Pesquisa e Prática Pedagógica), entendemos que essa pesquisa, necessária à formação de docentes, não pode ser confundida com os processos de "iniciação científica". A pesquisa necessária à formação de professores - e pedagogos -é aquela que permite o 'uso' de processos de pesquisa (desde a observação até a escrita sobre conhecimentos acumulados nos processos) sobre as atividades desenvolvidas nas práticas nas tantas redes educativas existentes e nas quais estes profissionais são chamados a atuar. (p. 500-50, grifos das autoras)

Ao referirem-se ao componente curricular Pesquisa e Prática Pedagógica, que, segundo as autoras teve sua origem em uma experiência no Curso de Formação de professores em Angra dos Reis (na década de noventa), sendo depois incorporado em muitas Universidades do país, Garcia e Alves (idem) destacam que se trata de um espaçotempo inovador dedicado à análise e critica continua das práticas pedagógicas e seus componentes.

O trabalho aqui apresentado agrega, à concepção de formação de professores de perspectiva crítica e emancipatória, as discussões da interculturalidade crítica como possibilidade de contribuir com a ruptura do caráter monocultural da escola. Conforme aponta Candau (2009), a perspectiva intercultural crítica [...] afirma o compromisso com a transformação política e social, proposto pela pedagogia crítica e, ao mesmo tempo, integra nesta perspectiva a importância das questões culturais (p. 40). Ao integrar de forma relevante 
as questões culturais, percebendo-as de forma a combater o caráter monocultural da escola, esta perspectiva:

[...] potencia processos de aprendizagem mais significativos e produtivos, na medida em que reconhece e valoriza cada um dos sujeitos neles implicados, combate todas as formas de silenciamento, invisibilização e/ou subalternização de determinados sujeitos socioculturais, favorecendo a construção de identidades culturais abertas e de sujeitos de direito, assim como a valorização do outro, do diferente, e o diálogo intercultural. (p. 43)

Com este entendimento e proposta intercultural crítica, o trabalho desenvolvido provocou doze estudantes do curso de Licenciatura em Pedagogia a trabalharem com questões raciais na escola pública em que participavam, por meio do Programa Institucional de Bolsa e Iniciação à Docência - PIBID/UNIRIO - mantido pela Coordenação de Aperfeiçoamento de Pessoal do Ensino Superior - CAPES.

O PIBID é um Programa proposto pela CAPES, por meio de Edital, para o qual concorrem professores de Instituições de Ensino Superior, apresentando projetos para o trabalho com escolas públicas, na formação de professores. Com o oferecimento de bolsas para os professores coordenadores do Projeto, e de subprojetos por área de formação, bolsas de supervisão para professores das escolas públicas envolvidas e, principalmente, bolsas para estudantes de cursos de licenciatura (Pedagogia e outras áreas de conhecimento), a proposta do Programa foi oportunizar a inserção do estudante de licenciatura na escola durante sua formação, contribuindo tanto com sua formação teórico-prática quanto com a integração dos cursos de formação de professores, em nível superior, com as escolas públicas.

Na UNIRIO, universidade em que o projeto se desenvolveu, a orientação do trabalho propôs a formação na docência de forma integrada às práticas de pesquisa, ou seja, as licenciandas ${ }^{\mathrm{iii}}$, os professores supervisores ${ }^{\mathrm{iv}}$ e os coordenadores de subprojeto $^{\mathrm{v}}$ desenvolveram pesquisa sobre e com a docência, com a escola, em grupos de discussão que, desde uma perspectiva qualitativa e dialógica, aprofundam questões que se apresentam como importantes no exercício da docência. O conceito de formação inicial de professores, portanto, mantêm-se como orientador do Programa e do projeto na universidade, mas é agregado da possibilidade de vivência da escola, para tornar suas questões como foco da formação e da pesquisa acadêmica, desde o início desta formação.

Na coordenação do projeto, lócus da enunciação das autoras deste trabalho, o projeto envolveu várias licenciaturas, mas, em foco neste momento, tomamos o trabalho com o grupo 
de doze discentes bolsistas, que atuam no primeiro segmento do Ensino Fundamental, encontros e debates sobre as observações feitas em sala de aula e sobre as oficinas ${ }^{\text {vi }}$ realizadas pelas discentes, duas vezes por semana.

Os grupos de discussão estudam os problemas vivenciados nas observações participantes que ocorrem nas aulas comuns dos alunos que participam das oficinas, produzem propostas de ação, aplicam as propostas e, novamente, refletem sobre as mesmas durante e após a aplicação. As possibilidades de se fazer pesquisa, nesse processo, são muitas, pois o estudo desenvolvido leva a situar os desafios no campo da produção de conhecimentos sobre os processos educativos e estes estudos estão relacionados à vivência das bolsistas nas escolas, o que as provoca para inquietudes próprias de uma pesquisa.

Um dos temas de estudo, provocados na observação à escola, foi sobre as relações raciais no cotidiano escolar. A preocupação com a temática racial teve como base a observação dos fatos que aconteciam em sala de aula e nas oficinas, situações em que as crianças e as professoras revelavam desconhecer a complexidade das relações raciais existentes no espaço escolar, no que se refere à população negra brasileira. Das doze bolsistas, seis ficaram sensibilizadas por esse olhar, pois duas fizeram sua monografia sobre o tema e quatro desenvolveram atividades pedagógicas também relacionadas ao tema.

O trabalho apresentado aqui foi desencadeado a partir de perguntas sobre (1) as possibilidades do projeto em construir uma perspectiva emancipatória de ensino e aprendizagem; (2) sobre a existência, ou não, do preconceito racial na escola e (3) sobre as possibilidades de se fazer um trabalho com os professores, visando a educação étnico-racial. Os depoimentos das 12 bolsistas foram tratados de forma a construir o Discurso do Sujeito Coletivo - DSC, um procedimento metodológico realizado a partir das falas dos sujeitos. Esse discurso é construído a partir de ideias centrais que se constituem em uma ou mais afirmações que vão traduzir o conteúdo essencial do discurso, em que os sujeitos expressam formalmente seus pensamentos e com expressões-chave que são transcrições literais de partes dos depoimentos. (LEFÈVRE; LEFÈVRE, 2001).

O DSC tem como um de seus pressupostos o resgate da fala do social. Esse resgate se daria por meio de depoimentos que, apesar de individuais, representam um determinado contexto social em que a voz de um é a voz do grupo coletivizado. Neste artigo, apresentam-se trechos de DCS, construídos com as falas das doze bolsistas, A seguir, retoma-se a relação entre educação e cultura, base da abordagem teórica realizada e a especificidade da educação 
intercultural, em diálogo com as questões étnico-raciais, na análise do Discurso do Sujeito Coletivo - DSC das bolsistas envolvidas no projeto.

\section{Educação e cultura: disputas do campo curricular}

Tal qual o campo da formação de professores, que é perpassado por propostas instrumentais, de caráter tecnicista e reducionista, em disputa com propostas de perspectiva crítica e dialógica que tomam a formação como espaço de profissionalização e práxis, o currículo também é produzido, como afirma Apple (2000), pelos conflitos, tensões e compromissos culturais, políticos e econômicos que organizam e desorganizam um povo. (p.

53). Neste sentido, o que é considerado como conhecimento e sua organização, quem pode ou não pode transmiti-lo, fazem parte de como a dominação e a subordinação são reproduzidas e alteradas nesta sociedade. (Ibid, p. 54). Continuando com as palavras do autor:

sempre há, então, uma política do conhecimento oficial, uma política que traduz o conflito entre o que alguns consideram simplesmente como descrições neutras do mundo e o que os outros veem como concepções de elite que dão poder a alguns grupos enquanto o tiram de outros. (Ibid, p. 54)

A defesa da padronização curricular, por meio do que é chamado por currículo mínimo (FREITAS, 2004), afirma-se no discurso da garantia de acesso a conhecimentos tomados como universais. O discurso do acesso aos conhecimentos universais é facilmente incorporado pela sociedade e o combate a este discurso, muitas vezes, é visto como uma proposta leviana de redução do papel da escola. Paro (2008), ao criticar a escola que tem por objetivo apenas transmitir conhecimentos, diz que a mesma:

Renuncia, assim, à pretensão de uma educação que provê as necessidades culturais da personalidade do ser humano numa perspectiva de integralidade, ao deixar de lado todos os demais componentes culturais: valores, arte, ciência, filosofia, direito, crenças, etc. O mais grave é que o problema não se reduz à pequenez do objetivo [transmissão de conhecimentos], mas inclui também o fato amplamente constatado de que, por pretender apenas isso, nem isso consegue realizar, visto que mesmo os conhecimentos e informações exigem, para serem assimilados e incorporados à personalidade do aprendiz, o envolvimento de outra dimensões culturais dessa personalidade, não considerados pela escola tradicional. (p.51) 
A formação de professores, orientada por perspectiva crítica e emancipatória, e o currículo percebido como campo de disputa entre conhecimentos, refletem-se, também em diferentes formas de entender e propor a formação escolar. $\mathrm{O}$ autor destaca o caráter cultural da formação humana como uma necessidade, numa perspectiva de integralidade. A cultura, neste caso, apresenta-se como um conjunto de saberes que perpassam as produções humanas advindas do seu processo de sobrevivência: valores, arte, ciência, entre outros. A formação humana, que se dá também por meio da escola, compreende um processo de apropriação que inclui mais que conhecimentos e informações. Pensar a escola, nesta dimensão ampla e humana, é pensar, também, uma escola intercultural.

Essas considerações nos levam a problematizar algumas concepções de Forquin (1993) sobre educação e cultura. O autor afirma que ao processo educativo escolar cabe $a$ responsabilidade de ter que transmitir e perpetuar a experiência humana considerada como cultura (p.13), por ele entendida como algo comunicável e memorável, tornado público, e que se cristalizou em saberes cumulativos e nos símbolos inteligíveis. A cultura seria, portanto, o conteúdo substancial da educação que a realiza como memória viva. Neste contexto, cultura não pode ser pensada sem educação e toda reflexão sobre uma desemboca imediatamente na consideração da outra. (p.14) São faces de uma mesma moeda que se complementam. Esta concepção se reforça pelo fato de que

\begin{abstract}
quer se tome a palavra "educação" no sentido amplo, de formação e socialização do indivíduo, quer se a restrinja unicamente ao domínio escolar, é necessário reconhecer que, se toda educação é sempre educação de alguém por alguém, ela supõe sempre também, necessariamente, a comunicação, a transmissão, a aquisição de alguma coisa: conhecimentos, competências, crenças, hábitos, valores, que constituem o que se chama precisamente de "conteúdo" da educação. Devido ao fato de que este conteúdo parece irredutível ao que há de particular e de contingente na experiência subjetiva ou intersubjetiva imediata, constituindo antes, a moldura, o suporte e a forma de toda experiência individual possível, devido, então, a que este conteúdo que se transmite na educação é sempre alguma coisa que nos precede, nos ultrapassa e nos institui enquanto sujeitos humanos, pode-se perfeitamente dar-lhe o nome de cultura. (FORQUIN, 1993, p. 10)
\end{abstract}

Se cultura é o conteúdo que se transmite na educação, como algo que nos precede, nos ultrapassa e nos institui como sujeitos humanos, conforme Forquin, como os alunos negros estão se constituindo como sujeitos? O que se questiona é que algo considerado válido como continuidade cultural para uns nem sempre o é para outros e, nesse sentido, não há uma só 
cultura. Poderíamos dizer, então, que as diferentes culturas seriam o conteúdo substancial da educação. É com essa preocupação que trabalhamos por uma educação intercultural crítica.

\section{Interculturalidade na sociedade e na escola}

O movimento intelectual tem, por meio de alguns estudiosos (SOUSA SANTOS, 2010; QUIJANO, 2010; entre outros), se dedicado a denunciar a epistemologia dominante que suprime os diferentes saberes produzidos do lado de cá do hemisfério, o hemisfério sul, denominando esses saberes de epistemologias do sul. Estes estudos dedicam-se a compreensão de como saberes particulares se constroem como universais e são reproduzidos como instrumentos de silenciamento e produção de subalternidades.

Ao distinguir as sociedades metropolitanas das sociedades coloniais, Sousa Santos (2010) identifica que, em ambas as sociedades, existem dicotomias que caracterizam pensamentos e realidades. Nas sociedades metropolitanas encontra-se a dicotomia regulação/emancipação $^{\text {vii }}$ e nas sociedades coloniais, a dicotomia apropriação/violência ${ }^{\text {viii }}$. Para o autor, o pensamento ocidental se constrói hegemônico por ser abissal, ou seja, por tomar como inexistente tudo o que lhe é externo, isto é, outras epistemologias e formas de ser e estar no mundo são apagadas. Este apagamento se constrói com base no status atribuído à ciência, que lhe permitiria definir o que é verdadeiro e o que é falso. Com este status e para manutenção do mesmo, produzem-se invisibilidades quanto a outras formas de conhecimento, tidos como populares, leigos, plebeus, camponeses, ou indígenas (SOUSA SANTOS, 2010, p. 33).

Aliado com esta forma de compreender, Quijano (2010) faz distinção entre os conceitos de colonialismo e colonialidade. Para ele, colonialismo refere-se a uma estrutura de dominação/ exploração onde o controle da autoridade política, dos recursos de produção e do trabalho de uma população domina outra, localizada em outra jurisdição territorial. (p. 84) Já colonialidade, apesar de estar vinculada ao colonialismo, é um dos elementos constitutivos e específicos do padrão mundial do poder capitalista. (p.84) Portanto, foi com a expansão capitalista que a colonialidade foi se configurando como um novo universo de relações intersubjetivas de dominação sob hegemonia eurocentrada. (p.85) A perspectiva da educação intercultural compartilha com estas compreensões.

Do ponto de vista intercultural, em nenhum lugar do mundo pode-se falar em cultura única e é preciso compreender que estamos todos imersos em uma multicultura. No entanto, a 
cultura privilegiada tem sido a cultura europeizada e, por esse motivo, outras culturas têm sido silenciadas, invisibilizadas e menosprezadas. É o caso da cultura afro-brasileira em nossa sociedade que, apesar da luta da população negra e de simpatizantes em mudar esse quadro, ainda encontra-se invisibilizada, em especial nas escolas.

Mais recentemente, grande parte da sociedade tem admitido a existência do preconceito racial $^{\mathrm{ix}}$ no Brasil e a necessidade de políticas públicas no intuito de combatê-lo. Entre essas políticas, as cotas raciais para o ingresso de negros nas universidades públicas e a promulgação da Lei 10.639/03 que instituiu as Diretrizes Curriculares Nacionais para a Educação das Relações Étnico-Raciais e para o Ensino da História e Cultura Afro-Brasileira e Africana, tornando obrigatória sua adoção em toda a educação básica. Mas, para que os professores tenham sensibilidade e construam saberes nessa direção, é necessário trabalhar em uma perspectiva intercultural.

Fleuri (2003) conceitua intercultura como um campo de debates que envolve diferentes identidades étnicas, de gênero, de geração, de diferenças físicas e mentais, entre variadas concepções e propostas que enfrentam a questão da relação entre esses processos identitários e socioculturais diferentes.(p.22) Portanto, a interculturalidade envolve mais do que a simples tolerância ao outro. É preciso colocar-se no lugar do outro, em um processo autêntico de alteridade.

Candau (2008), buscando em Walsh (2001, p.10-11) o conceito de interculturalidade crítica, diz que é um intercâmbio que se constrói entre pessoas, conhecimentos, saberes e práticas culturalmente diferentes, buscando desenvolver um novo sentido entre elas na sua diferença. (p. 52)

O desenvolvimento desse novo sentido é responsável por práticas e saberes emancipatórios ${ }^{\mathrm{x}}$ provocados pelo intercâmbio construído entre pessoas. A experiência desenvolvida no PIBID, mais especificamente entre bolsistas do Pibid que vivenciavam o projeto Pedagogia/ Ensino Fundamental/ UNIRIO, em uma escola pública municipal e crianças que frequentavam as oficinas, orientava-se por essa forma de entender o processo ensinoaprendizagem.

No decorrer dos trabalhos, cerca de cem crianças foram atendidas nas oficinas, em seis turmas dos anos iniciais do ensino fundamental, onde estas crianças estudavam, sendo acompanhadas na realização da observação participante ${ }^{x i}$. Ao final de cada ano letivo, as 
bolsistas, entre outras atividades, responderam a um questionário que serviu de base para a construção do Discurso do Sujeito Coletivo - DSC aqui apresentado.

O sentido do trabalho escolar a ser realizado na escola tem sido buscado, permanentemente, com muito respeito e interesse pelo que cada criança tem a contar sobre seus gostos e vivências. Essa busca tem permitido descobertas que levaram as bolsistas a trabalharem com formas de expressão e linguagens que, muitas vezes, são inexistentes para a escola: o funk, o desenho animado Chaves, o futebol, a cultura dos países latinos, a confecção de bonecas abayomi ${ }^{x i i}$, entre outros trabalhos. Tal prática levou as doze bolsistas perceberem que o processo de ensino e aprendizagem pode ser emancipatório:

O Pibid tem contribuído para uma perspectiva emancipatória, pois orientamos nossos alunos a produzirem seus próprios caminhos de conhecimento através da liberdade que temos para trabalhar, valorizando seus saberes, curiosidades e culturas. É possível observar muito do que temos na teoria, na prática dos professores e dialogar com as ações em nossas oficinas, de forma a contribuir com o aluno, com a professora e com a escola, trazendo assim uma nova relação com o processo de ensino-aprendizagem. (DSC) iiii

Considerando que uma prática educativa pautada na interculturalidade crítica é uma prática emancipatória, a educação étnico-racial precisa ser contemplada dentro desta concepção. O estudo das Diretrizes Curriculares Nacionais para a Educação das Relações Étnico-Raciais e para o Ensino de História e Cultura Afro-Brasileira e Africana foi realizado com as bolsistas. Alguns aspectos deste estudo merecem ser destacados.

O primeiro deles refere-se ao conteúdo das Diretrizes. Ele, por si só, já se constitui em um rico material a ser explorado pelos professores. As Diretrizes trazem, por exemplo, três princípios que se desdobram em 20 orientações e encaminhamentos. O primeiro princípio consciência política e histórica da diversidade - já no seu início, conduz (conduzir é o verbo utilizado no texto) para a igualdade básica de pessoa humana como sujeito de direitos. (BRASIL, 2004, p. 18). O professor que não é especialista em História da África pode trabalhar em prol de uma educação étnico-racial procurando adotar posturas emancipatórias e realizar atividades com essa intenção.

O segundo princípio - fortalecimento de identidades e de direitos - orienta para, entre outras coisas, romper com imagens negativas forjadas por diferentes meios de comunicação, contra os negros e os povos indígenas. (Idem,p.19). O terceiro princípio - ações educativas de 
combate ao racismo e discriminações - encaminha, de início, para a conexão de objetivos, estratégias de ensino e

atividades com a experiência de vida dos alunos e professores, valorizando aprendizagens vinculadas às suas relações com pessoas negras, brancas, mestiças, assim como as vinculadas às relações entre negros, indígenas e brancos no conjunto da sociedade.(Ibidem,p.19-20)

Como o próprio documento destaca, estes princípios e seus desdobramentos mostram exigências de mudança de mentalidade, de maneiras de pensar e agir dos indivíduos em particular, assim como das instituições e de suas tradições culturais.(BRASIL, 2004,p.20) Ou seja, é preciso repensar a cultura da escola em que ainda prevalecem conhecimentos universais que desprezam conhecimentos e saberes locais, deixando-se de perceber o outro em suas particularidades e culturas próprias. Este foi o primeiro passo no trabalho investigativo das bolsistas para realização do planejamento das oficinas, um tanto difícil, mas permitiu que refletissem sobre quais culturas e saberes locais não estavam sendo percebidos pela escola.

Mesmo as pessoas que convivem sob o mesmo teto pensam de forma diversa porque são de diferentes gerações e formadas em um contexto histórico distinto, portanto, a ideia "milenar" que nos incita a amar os demais como a nós mesmos, é difícil de entender, de praticar, porque na prática não somos iguais (ITURRA, 1996). Se não há essa discutível igualdade, mesmo entre as pessoas convivendo sob um mesmo teto, o que se pode dizer, então, das relações pessoais em uma escola? Diferentes ideias comportam também uma diversidade de formas de encarar a prática cotidiana.

Existe no Brasil uma concepção de que a discriminação contra os negros é somente uma questão de classe, mas a discriminação contra o negro é também uma questão de cultura, pois a sua imagem é apresentada de forma estereotipada, estigmatizada, sendo a desconstrução desta imagem, na educação escolar, um processo mais difícil, exigindo um projeto mais sistemático de crítica da escola. Tal crítica envolveria entre outras coisas uma revisão mais comprometida das mensagens dos livros didáticos e mudanças nos currículos. Nesse sentido, o conhecimento sobre diferentes culturas e a inter-relação entre elas faz-se necessário.

As bolsistas do Pibid foram indagadas se percebiam a existência de preconceito racial na escola em que atuavam. Entre as doze, seis responderam que percebiam.

Durante esses dois anos, percebo também que a relação dos alunos brancos com os alunos negros não foi muito satisfatória, pois havia muitas brigas e 
exclusões. As crianças brancas, na maioria das vezes, chamavam os colegas negros de burros, sem contar alguns episódios onde alguns alunos diziam "Tia, não quero fazer com esse macaco não!”. As relações entre alunos negros e brancos, à primeira vista é normal, porém observando de uma forma mais crítica conseguimos ver uma ou outra criança sendo deixada para trás em brincadeiras, reclamações de implicância ou desprezo. (DSC) ${ }^{\mathrm{xiv}}$

Essa implicância ou desprezo termina por influenciar no rendimento escolar dos alunos. Müller (2009) destaca vários motivos, baseados em pesquisas, para o insucesso escolar da população negra que vão para além da pobreza:

i) as escolas que as crianças negras frequentam têm qualidade de ensino inferior; ii) os negros costumam desenvolver uma autoimagem negativa, provocada pela forma como a negritude é vista pela sociedade brasileira; iii) a existência, nas escolas, de preconceito racial contra o negro, tanto por parte dos alunos como por parte dos professores; iv) conteúdos dos livros didáticos que expressam discriminação racial e v) o despreparo dos professores e demais profissionais da educação em lidar com as situações de racismo que acontecem frequentemente no cotidiano escolar. (p.33)

Portanto, para percebermos a importância de se trabalhar por uma educação étnicoracial e adotar práticas educativas interculturais críticas, é necessário educar o olhar para eventos cotidianos que à primeira vista parecem ser inofensivos ou brincadeiras de criança. No decorrer do processo ensino-aprendizagem, atividades que provoquem atitudes de respeito, entre outras ações, devem ser constantemente realizadas. Para tratar mais especificamente do tema, duas bolsistas realizaram oficinas de contação e construção de histórias, com a confecção, pelas crianças, de bonecas abayomie e trabalharam com filmes e textos sobre a capoeira. $\mathrm{O}$ objetivo dessas atividades era conhecer e valorizar a cultura afro-brasileira.

Outra atividade realizada, com todas as crianças que frequentavam as oficinas do Pibid, foi a exibição do filme Kiriku e a Feiticeira. O filme conta a história de Kiriku um garoto muito pequeno, mas muito inteligente e com dons especiais, que nasceu em uma pequena aldeia sob a maldição da cruel feiticeira Karaba que secou as fontes de água e sequestrou todos os homens da região. A feiticeira foi vencida pela coragem e pela astúcia de Kiriku que a enfrenta junto com seus guardiões e, nesta luta, ele aprende que só o amor, a verdade e a generosidade, aliados à inteligência, são capazes de vencer a dor e as diferenças. A intenção era mostrar um pouco da cultura africana, bem como contribuir para uma desconstrução de possíveis estereótipos, além de proporcionar um herói diferente daqueles que são "normalmente" apresentados. Essa 
atividade foi feita com a parceria de uma bolsista de Iniciação Científica que estuda a temática das relações raciais na escola.

Algumas crianças disseram que a África era um país. Outras disseram que na África só tem "pretos" (palavra dos alunos), e quanto ao Brasil, aqui tem mais morenos. E alguns desenharam animais da savana africana. Enfim, desconstruir mentalidades hegemônicas não é tarefa simples. As bolsistas alegaram que apesar de alguns trabalhos já terem sido feitos, as professoras das turmas não colaboraram com atividades que pudessem reforçar essa visão. Destaca-se que essa desconstrução se faz em um processo contínuo de atividades que envolvam a valorização da cultura e do continente africano.

Perguntando-se às bolsistas sobre as possibilidades de fazer um trabalho visando a educação étnico-racial, com os professores, somente uma respondeu não acreditar que teria boa acolhida porque não havia visto uma atividade sequer explorando a temática. As demais, onze, responderam que acreditavam ser possível.

A questão racial dentro da escola seria muito bem acolhida pelos professores, pois constantemente eles devem presenciar fatos relacionados ao tema. E visto que essa temática gira em torno de nossa sociedade diariamente, não somente dentro da escola, Seria uma forma também de trabalhar com o cotidiano escolar e o conhecimento proporcionado aos alunos não ficaria pautado somente em livros e conteúdos do caderno. A questão racial já foi tratada em nossos trabalhos e tudo sempre correu bem. (DSC) ${ }^{\mathrm{xv}}$

Apesar dessa opinião favorável, ao discorrer sobre a postura dos professores frente à temática, as pesquisas realizadas pela Universidade Federal de Mato Grosso e coordenadas por Müller (2009) observam que, em escolas desse estado, a relação entre professores e alunos negros, muitas vezes, expressam a falta de proteção a qual o aluno negro está submetido, diante de situações de agressão física e/ou moral. Nas palavras da autora,

[...] professores não percebem que tratam de forma diferente os alunos de pele mais escura. São mais exigentes, são mais rigorosos. Não reconhecemos progressos desses estudantes, pelo contrário, estereotipam negativamente seu desempenho escolar. Evitam trocas afetivas com crianças negras sejam verbais - elogios, palavras carinhosas, etc. - sejam físicas. Alguns chegam mesmo a rechaçar o contato físico com esses alunos. (MÜLLER, 2009, p. 38)

Uma das formas de enfrentar o problema, na educação, seria exercitar-se, eticamente, diante de situações racistas vivenciadas pelo educador, como nos alerta Gomes (2006). Nas suas palavras, não podemos continuar nos escondendo atrás de um currículo escolar que 
silencia, impõe estereótipos e lida de maneira desigual, preconceituosa e discriminatória com as diferenças presentes na escola. (p.24)

Sabe-se que não é tarefa fácil inserir no currículo - tanto no praticado quanto no prescrito - conteúdos que estejam mais próximos da população negra brasileira, mas como diz a autora, se quisermos compreender a complexa trama entre diversidade cultural e currículo, teremos de enfrentar o debate sobre as desigualdades sociais e raciais em nosso país.(p.25) Utilizando ainda as palavras da autora:

\begin{abstract}
Nossos alunos e alunas, ao passarem pela educação básica, precisam vivenciar práticas pedagógicas que lhes possibilitem ampliar seu universo sociocultural, rever e superar preconceitos, eliminar toda e qualquer forma ou comportamento discriminatório em relação ao outro. Uma tarefa difícil? Sim, sem dúvida. Porém, essa é a tarefa de qualquer educador, tanto na escola pública quanto na privada. Não há como ser educador sem assumir essa postura política, ética e pedagógica. (GOMES, 2006,p.26)
\end{abstract}

Adotar uma postura política, ética e pedagógica, diante de situações que envolvam relações raciais no cotidiano escolar, exige de todos que vivenciam essa realidade - toda a comunidade escolar - trabalhar com outros saberes, outras lógicas que vão para além do pensamento linear e positivista que acomete, atualmente, parte dessa comunidade.

\title{
Considerações Finais
}

Este trabalho apresentou o desenvolvimento de um projeto dedicado à formação de pedagogos, realizado por meio do Programa Institucional de Bolsa de Iniciação à Docência PIBID, que teve como objetivo discutir as possibilidades para a formação sobre relações raciais no cotidiano escolar.

Para compreensão do trabalho realizado, apresentou as concepções de formação de professores que orientam a experiência desenvolvida, entendida como crítica, emancipatória e intercultural. Esta concepção de formação de professores é orientadora também da perspectiva curricular adotada na discussão do conteúdo escolar.

Em comum, todo o trabalho realizado se orienta pelos desafios da formação de professores comprometida com o tornar visível outros conhecimentos e objetivos de trabalho da escola, que não a exclusiva transmissão de conteúdos e informações tomadas como universais. 
Por meio da interculturalidade crítica - aqui brevemente definida como valorização da compreensão dinâmica de cultura, expressa no diálogo de diferentes perspectivas que, ao tornarem visíveis o que antes estava invisibilizado, contribui para romper com os processos de subalternização - provoca-se as pedagogas em formação, doze bolsistas do PIBID/UNIRIO, a confrontarem-se entre a formação teórica desenvolvida na universidade e o cotidiano da escola onde propõem desenvolver atividades de observação participante nas salas de aula comuns e oficinas no contra-turno escolar.

As situações vivenciadas na escola, com as bolsistas, revelaram o quanto é importante proporcionar, no curso de formação de professores, debates sobre a problemática racial da população negra para que seja possível refletir sobre a situação desvantajosa em que se encontra essa população em relação à população branca, revelando que um professor, ao desconhecer sua postura de não visualização do preconceito racial em sala de aula, reforça tal preconceito e está reforçando uma ideologia ainda muito presente em nossa sociedade.

Se é fato que muitos professores veem seus alunos negros de forma inferiorizada, não vão perceber a existência do preconceito racial e, se não o percebem, nada fazem para minimizá-lo, considerando, muitas vezes, que atitudes preconceituosas não passam de “intriguinhas”. Assim, ao aproximarem-se com aporte teórico dos problemas práticos observados na escola, o Discurso do Sujeito Coletivo destas estudantes revela a possibilidade do trabalho desenvolvido no âmbito do projeto como um trabalho que oferece condições de reconhecer os estudantes como sujeitos de saberes, curiosidades e culturas, relevantes para sua formação escolar.

Um desses problemas práticos é o comportamento tímido de certas crianças em executar tarefas que exigem expressão oral. Ficam com vergonha de ler ou falar sobre algo, pois temem o julgamento crítico dos colegas, dos professores ou das bolsistas. Percebemos que, muitas vezes, essa vergonha está associada à insegurança ou desvalorização de si próprio. Como esse comportamento acontece com várias crianças que participam das oficinas e muitas são negras, é possível inferir que tal fato deve-se, em parte, ao sentimento de inferioridade que a criança negra sente em relação ao seu mundo, a sua cultura, às suas origens.

Nesse sentido, uma proposta de ação educativa intercultural crítica e étnico-racial requer novas posturas, novos conhecimentos, valorização de outros saberes e como dizem Oliveira e Candau (2010), requer a superação de padrões epistemológicos hegemônicos no seio da intelectualidade brasileira. (p.38) 
O debate sobre a diversidade de leituras da situação global de nosso tempo tem estado ausente dos sistemas educativos, ocorrendo à margem, sem penetrar nos currículos escolares e como bem postula Sousa Santos (1996), um projeto educativo emancipatório tem que colocar o conflito cultural no centro do currículo. Mas, as dificuldades para fazer isso são enormes devido à resistência e à inércia dos mapas culturais dominantes e porque a comunicação continua a ter muitos obstáculos e a ser seletiva. Mesmo algumas políticas contra-hegemônicas, nas suas versões mais radicais, contribuem para a criação de guetos culturais.

O projeto educativo emancipatório precisa definir a natureza do conflito cultural e inventar dispositivos que facilitem a comunicação. $\mathrm{O}$ conflito cultural não ocorre no seio da mesma cultura, mas, antes num espaço intercultural que precisa ser construído para que haja comunicação.

Enfim, o campo educativo precisa criar espaços pedagógicos para a interculturalidade crítica; criar imagens desestabilizadoras da ideia de que existe uma cultura universal - leia-se eurocêntrica - e de que existe uma hierarquização entre as culturas. Ao fim dessas reflexões, pode-se inferir que os desafios postos, nesse século, são múltiplos e os profissionais da educação que trabalham nos cursos de formação de professores não podem mais fechar os olhos para esses desafios que nos apresentam. Se, como diz Sousa Santos (1996), as identidades são identificações em curso, não há motivos para nos conformarmos com uma identidade profissional docente alheia aos apelos que estão sendo feitos em prol de uma educação étnico-racial para a sociedade.

\section{Referências}

APPLE, Michael W. Política Cultural e Educação. Tradução de Maria José do Amaral Ferreira. São Paulo: Cortez, 2000.

BRASIL. Diretrizes Curriculares Nacionais para a Educação das Relações Étnico-raciais e para o Ensino de História e Cultura Afrobrasileira e Africana. Ministério da Educação. Brasília. Conselho Nacional de Educação, 2004.

BRZEZINSKI, Iria. Políticas contemporâneas de formação de professores para os anos iniciais do ensino fundamental. Educ. Soc., Campinas, v. 29, n. 105, Dec. 2008. Disponível em <http://www.scielo.br/scielo.php?script=sci_arttext\&pid=S0101$73302008000400010 \& \operatorname{lng}=\mathrm{en} \& n r m=i s o>$. Acessado em 19 abril 2013. 
CANDAU, Vera M. Direitos Humanos, educação e interculturalidade: as tensões entre igualdade e diferença. Revista Brasileira de Educação. V. 13, n. ${ }^{\circ}$ 37.ANPED. Jan./Abr. 2008. p. 45-56.

CANDAU, Vera. Memória(s), Diálogos e Buscas: aprendendo e ensinando didática. In CANDAU, Vera. (org.) Didática: questões contemporâneas. Rio de Janeiro: Forma \& Ação, 2009. p. 29-62.

FLEURI, Reinaldo Matias. Intercultura e educação. Revista Brasileira de Educação. ․․ ${ }^{\circ}$ 23.ANPED. Maio/Jun./Jul./Ago.2003. p. 16-35.

FORQUIN, Jean-Claude. Escola e Cultura: as bases sociais e epistemológicas do conhecimento escolar. Trad.: Guacira Lopes Louro. Porto Alegre: Artes Médicas Sul, 1993.

FREITAS, Helena C. L. Novas políticas de formação: da concepção negada à concepção consentida. In BARBOSA, Raquel L.L. (Org.) Trajetórias e perspectivas da formação de professores. São Paulo: Editora UNESP, 2004.

GARCIA, Regina Leite e ALVES, Nilda. Sobre formação de professores e professoras: questões curriculares. In: LIBÂNEO, José Carlos e ALVES, Nilda (orgs.) Temas de Pedagogia: diálogos ente didática e currículo. São Paulo: Cortez, 2012, p. 489-510.

GOMES, Nilma Lino. Diversidade cultural, currículo e questão racial: desafios para a prática pedagógica.In: ABRAMOWICZ, Anete; BARBOSA, Lucia Maria de Assunção; SILVÉRIO, Walter Roberto (Orgs.).Educação como prática da diferença. Campinas, SP: Armazém do Ipê (Autores associados), 2006. p.21-40

ITURRA, Raul. La escuela como lugar de ciudadanía. Sociológica. Revista de Pensamiento Social. No 2. Espanha, Noviembre, 1996.

KIRIKÚ E A FEITICEIRA. Direção: Michel Ocelot. Paulinas Multimídias, 70 min, 2002 LEFÈVRE Fernando; LEFÈVRE Ana Maria C. Os Novos Instrumentos no Contexto da Pesquisa Qualitativa. In. LEFÈVRE Fernando; LEFÈVRE Ana Maria C TEIXEIRA Jorge Juarez V(orgs). O Discurso do Sujeito Coletivo. Caxias do Sul, Rio Grande do Sul: EDUCS,. 2000.

MÜLLER, Maria Lucia Rodrigues. Formação de professores e perspectivas para a implantação da lei 10.639/03. In: SOUZA, Maria Elena Viana. Relações Raciais no Cotidiano Escolar. Diálogos com a Lei 10.639/03. Rio de Janeiro: Rovelle, 2009.

OLIVEIRA, Luiz Fernandes de; CANDAU, Vera Maria Ferrão. Pedagogia decolonial e educação antirracista e intercultural no Brasil. Educação em Revista. Belo Horizonte. V. 26. N.01. Abr.2010. p.15-40.

PARO, Vitor H. Educação como exercício do poder: crítica ao senso comum em educação. São Paulo: Cortez, 2008. 
QUIJANO, Anibal. Colonialidade do poder e classificação social. In: SANTOS, Boaventura de Sousa; MENESES, Maria Paula. (Org.). Epistemologias do Sul. São Paulo: Cortez, 2010.p. 84-130.

SOUSA SANTOS, Boaventura de. Para Uma Pedagogia do Conflito. In: SILVA, Luiz H. et al (orgs.) Novos Mapas Culturais - Novas Perspectivas Educacionais. Porto Alegre: Editora Sulina, 1996.

Para além do pensamento abissal: das linhas globais a uma ecologia de saberes. In: SANTOS, Boaventura de Sousa; MENESES, Maria Paula. (Org.). Epistemologias do Sul. São Paulo: Cortez, 2010.p. 31-83.

WALSH, Catherine. La educación intercultural em la educación. Peru: Ministerio de Educación, 2001. Mimeografado.

\footnotetext{
${ }^{\text {i }}$ Professora associada na Universidade Federal do Estado do Rio de Janeiro/UNIRIO, Departamento de Didática e PPGEdu/UNIRIO.

ii Professora adjunta na Universidade Federal do Estado do Rio de Janeiro/UNIRIO, Departamento de Didática, Coordenadora PPGEdu/UNIRIO.

iiiTodas do sexo feminino.
}

${ }^{\text {iv }}$ Dois professores da escola pública envolvida no projeto recebem bolsa da CAPES para supervisão do trabalho das bolsistas.

${ }^{v}$ Professoras da universidade, autoras deste trabalho, exercendo a função de coordenação do projeto e do programa, no período em que a experiência foi desenvolvida.

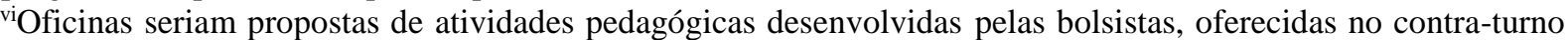
escolar, considerando-se os mais variados interesses das crianças, suas vivências culturais, alguns conteúdos trabalhados em sala de aula e, ainda, a formação de uma auto estima positiva que traria novas formas de se ver e de se relacionar com as pessoas.

vii $\mathrm{O}$ pilar da regulação social é constituído pelos princípios do Estado, da comunidade e do mercado. O da emancipação consiste nas três lógicas da racionalidade: a estético-expressiva das artes e literatura; a instrumental cognitiva da ciência e tecnologia e a moral-prática da ética e do direito. (SANTOS, 2010, p.32)

viii A dicotomia apropriação/violência, que está do 'outro lado da linha', está fundamentada em uma realidade e uma produção consideradas inexistentes. Inexistência significa aqui a exclusão porque permanece exterior ao universo que a própria concepção aceite de inclusão considera como sendo o Outro. (Idem)

ix Vários são os preconceitos que carregamos, mas para esse artigo tratamos somente do preconceito racial contra a população negra brasileira que durante muito tempo foi camuflado pelo mito da democracia racial, reforçada pela obra de Gilberto Freire, Casa Grande e Senzala.

${ }^{\mathrm{x}}$ Entendemos por práticas e saberes emancipatórios, aqueles que visam romper com as ideologias conservadoras, transformar subjetividades por meio de reflexões críticas e coletivas, conforme Paulo Freire nos ensinou.

${ }^{x i}$ As bolsistas, em duplas, acompanhavam um dia da semana a aula comum, apoiando as crianças indicadas pelas professoras para as oficinas, e colaborando com a professora nas atividades solicitadas. E, em um dia da semana, no contraturno, ofereciam, também em duplas, oficinas para desenvolvimento de trabalhos que atendessem a diversidade de interesse das crianças.

xii As bonecas abayomi são bonecas pretas, artesanais, elaboradas com retalhos de pano em que não são utilizadas cola ou costura, apenas nós e com pouquíssimo uso de ferramentas.

xiii A pergunta geradora para a construção desse Discurso do Sujeito Coletivo (DSC) foi: O Pibid tem contribuído para uma perspectiva emancipatória da docência? As expressões-chave e as ideias centrais destacadas dos discursos foram: saberes, vivências, construção de conhecimento e relação teoria-prática.

${ }^{\text {xiv }}$ As ideias centrais e expressões-chave neste DSC seriam: relação entre alunos brancos e negros não muito satisfatória, cenas de racismo, preconceito racial em sala de aula e alunos negros sendo os últimos a serem escolhidos para participar de brincadeiras. 
${ }^{\mathrm{xv}}$ As ideias centrais e as expressões chave giraram em torno de que é possível fazer um trabalho, com os alunos e com os professores, relacionado à questão racial e que a questão racial já foi tratada em nossos trabalhos e tudo sempre correu bem. 